\title{
Effect of Supertargeting and Non Isothermal Stream Mixing in Heat Exchanger Network Design Using Modified Pinch Analysis
}

\author{
Azeez Oluwatosin Sarafa ${ }^{1,}$, Ogbonnaya Blessing ${ }^{1}$, Ekechukwu Onyinye ${ }^{1}$, Akande Hassan ${ }^{2}$ \\ ${ }^{1}$ Department of Chemical Engineering, Federal University of Technology, Minna, Nigeria \\ ${ }^{2}$ Department of Chemical Engineering, Kaduna Polytechnic, Kaduna, Nigeria
}

Email address:

tosin.azeez@futminna.edu.ng (A. O. Sarafa)

${ }^{*}$ Corresponding author

\section{To cite this article:}

Azeez Oluwatosin Sarafa, Ogbonnaya Blessing, Ekechukwu Onyinye, Akande Hassan. Effect of Supertargeting and Non Isothermal Stream Mixing in Heat Exchanger Network Design Using Modified Pinch Analysis. International Journal of Energy and Environmental Science. Vol. 4, No. 1, 2019, pp. 18-26. doi: 10.11648/j.ijees.20190401.13

Received: January 30, 2019; Accepted: March 21, 2019; Published: May 11, 2019

\begin{abstract}
This paper investigated the effect of minimum temperature difference as well as that of non-isothermal stream mixing in heat exchanger networks (HENs) using a modified pinch technique. Supertargeting was carried out to determine the appropriate minimum temperature difference value used to design the HENs. The networks were further optimized to remove the isothermal mixing assumption. In the four case studies used in this work, each shows how these two concepts affect the total annual cost (TAC) of HENs. These were presented in the network comparison tables where the cost of the networks using supertargeting is much lower than the cost of the ones without, and the non-isothermal mixing networks have lower costs than the ones with the isothermal mixing assumption even in the networks designed without supertargeting technique.
\end{abstract}

Keywords: Supertargeting, Optimization, Non-Isothermal Mixing, Pinch Analysis

\section{Introduction}

Heat exchanger network synthesis (HENS) can be done with the aim of finding a heat exchanger network (HEN) that provides the minimum total annualized cost for a process. This can be achieved either through a sequential method such as pinch analysis [9], or simultaneously through mathematical programming technique $[7,3,4]$, or with a combination of both methods $[2,8]$.

HENS can be carried out simultaneously using Mathematical programming, which solves the problem as a Mixed Integer Non-Linear Programming (MINLP) by optimizing utility costs, number of units and heat exchanger areas, all simultaneously [4]. Pinch Analysis as a thermodynamic based method of process integration is used in the sequential design of HENs that obey pinch principles and pinch design rules by setting targets, using Composite curves and minimum temperature difference and supertargeting technique [9]. The minimum temperature difference in a heat exchanger network $\Delta T_{\min }$ is the smallest temperature difference that should exist between hot and cold streams in a heat exchanger for the HEN to be optimal. It is the temperature difference at the pinch point in the composite curves [15].

Supertargeting is the cost optimization tool of pinch analysis, that determines the optimum $\Delta T_{\min }$ value by considering energy and capital costs tradeoff. The $\Delta T_{\min }$ value is important in HENS as it directly affects the Energy Target which determines the operating cost and the Heat Exchanger Area Target that controls the capital cost of the network. The smaller the $\Delta T_{\min }$ value, the lower the energy target but the higher the area target and vice versa. Hence Supertargeting is vital for the design of a globally optimum network $[10,9,11]$.

HENS is mostly done with the assumption of isothermal stream mixing between split streams where all split sub streams of a stream exit at the same temperatureand assumed to mix isothermally at the junctions. This assumption was initiated by Yee and Grossmann [13], to eliminate non-linear mixing equations in the constraint equations of the mixers 
and exchangers, it reduces the problem's dimension and makes it easier to solve. It was used byAzeez et al [3] and compared with non-isothermal stream mixing by Bjork and Westerlund [4]. Thelimitation of this assumption is that it leads to the design of sub optimal networks, as it overestimates the area cost due to the restriction it places on area trade-offs between the heat exchangers on the split streams [6].

Although the Isothermal mixing assumption makes the HENS more manageable by removing non-linear heat balances in the constraints, it does so at the expense of some important HEN configurations [8]. This can be corrected by the optimization of the designed network using a MINLP formulation that incorporates non-isothermal stream mixing in HENS, while introducing a number of bilinear terms that were excluded by the isothermal mixing assumption $[4,8]$. The optimization could be done for the objective function of minimizing area, with split flow ratios and temperatures before mixers as the optimization variables [4] or for the objective function of minimizing total annualized cost (TAC), with split flow ratios and heat exchanger loads as the optimization variables as used by Aspen Energy Analyzer in this paper $[1,2]$.

Aspen Energy Analyzer is a heat integration software that combines traditional pinch analysis with mathematical programming for the design and optimization of heat exchanger networks (HEN) along with minimum total annual cost (TAC) for a process [12]. It designs the heat exchanger network using either pinch design method [9] or mathematical programming using its Automatic Recommend Design featurethat involves a Linear Programming model and two Mixed Integer Linear Programming (MILP) steps. The software's optimization tool optimizes the designed network considering degrees of freedom, feasibility of heat exchangers, temperatures specifications among other things, with the objective function of either minimizing TAC or the network's area [2].
In this paper, HENs designed using Modified Pinch Analysis on Aspen Energy Analyzer, Version 8.8 was compared with those designed by Bjork and Westerlund [4] in their "global optimization" using the Synheat Model [14]. This research brings to limelight the effect of non-isothermal stream mixing and minimum temperature difference $\Delta T_{\min }$ on the total cost of HENS.

\section{Problem Statement}

There are hot streams in need of cooling and cold streams in need of heating in every plant, these energy needs can be satisfied using external utilities that increase the total cost of production. To achieve minimum total annual cost, the process heat can be conserved through synthesis of a heat exchanger network to exchange heat from the hot streams to heat as much of the cold streams as possible, maximizing process-process heat recovery and at the same time reducing the need for external utilities.

The heat exchange network can easily be synthesized with enough process information; heat capacity flow rates, supply and target temperatures and heat transfer coefficients of the process streams; costs, supply and target temperatures and heat transfer coefficient for the utilities as well as the annual operating time, capital cost index and the annualization factor.

\section{Methodology}

The modified pinch technique adopted in this research as viewed by the authors is as provided in Aspen Energy Analyzer [1]. It was used to optimize the total annual cost (TAC) of heat exchanger networks discussed in this work. Process data were collected from literature [4], such as the supply and target temperatures, heat transfer coefficients, heat capacity flow rates of the streams, capital cost index and cost of external utilities. Input of the extracted data into the Aspen Energy Analyzer user interface shown in Figure 1.

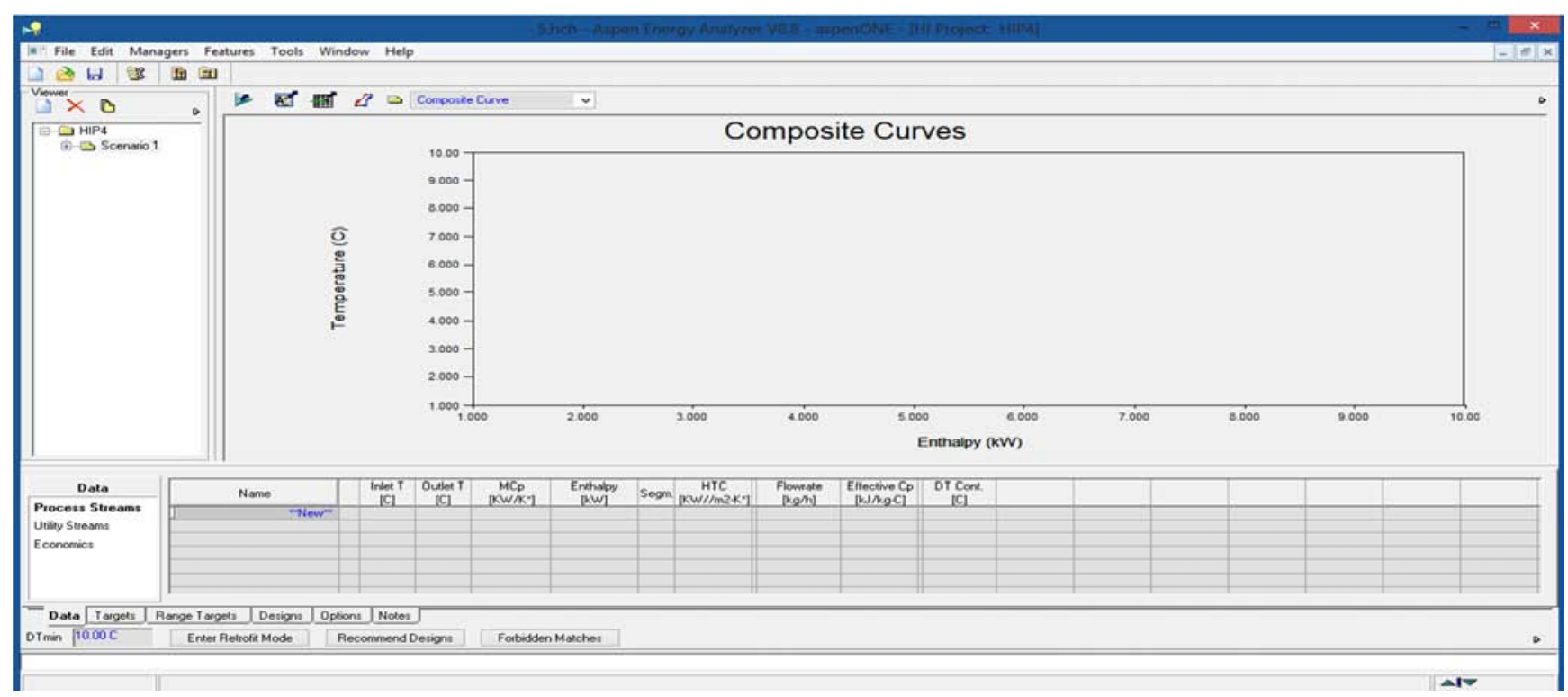

Figure 1. Aspen Energy Analyzer Version 8.8's user interface. 
Supertargeting was carried out to determine the optimum $\Delta T_{\min }$ value, by plotting targeted Total Annual Cost against the various values of minimum temperature difference in the heat exchanger network. Then, the heat exchange network was designed in the software's grid diagram using the $\Delta T_{\min }$ value and pinch design rules [10] under isothermal stream mixing assumption, the designed network was further optimized using the software's optimization tool to remove the isothermal mixing assumption and bring about a non isothermal stream mixing network. Finally, the design process is then repeated at other $\Delta T_{\min }$ values of to show the effect of $\Delta T_{\min }$ in HENS.

\section{Result and Discussion of Results}

Four heat exchanger analysis problems were solved in this work, which focused on the effect of the non isothermal stream mixing assumption and that of the minimum temperature difference $\Delta T_{\text {min }}$ obtained from supertargeting using Aspen Energy Analyzer.

\subsection{Case Study 1}

This is a 3-stream problem, whose stream and cost data is shown in Table 1. The supertargeting curve for this problem shown in Figure 2 gives the network's $\Delta T_{\min }$ as $10^{\circ} \mathrm{C}$, the HEN designed using pinch design rules on Aspen Energy Analyzer obtained a total cost of $\$ 35,848$ (Figure 3). On optimization using the aspen energy analyzer's optimization tool to remove the isothermal stream mixing assumption, the network with non-isothermal stream mixing as in Figure 4 had a total annual cost of $\$ 35,051$. These networks were compared in Table 2, using total annual cost at different $\Delta T_{\min }$ values with those designed by Bjork and Westerlund [4] to show the effect of supertargeting on the total annual cost of a network.

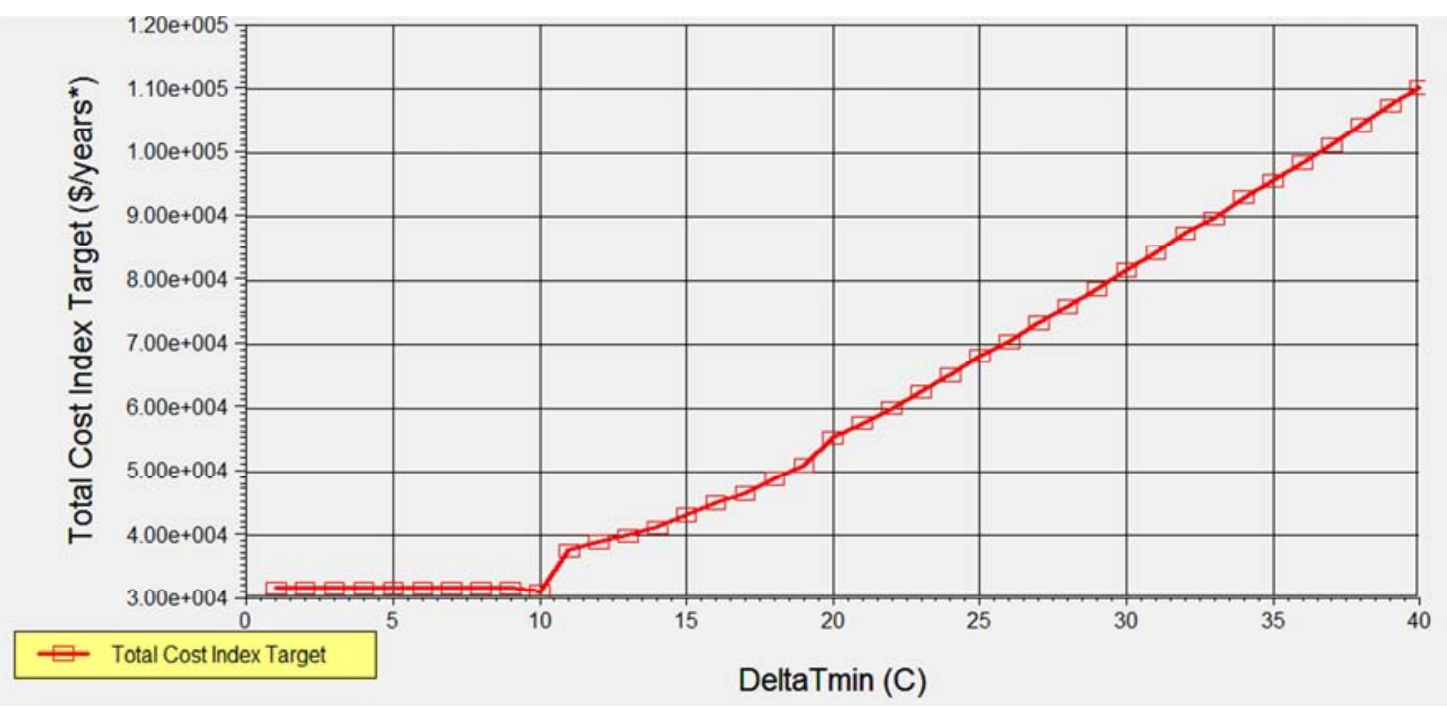

Figure 2. Supertargeting curve for case study 1.

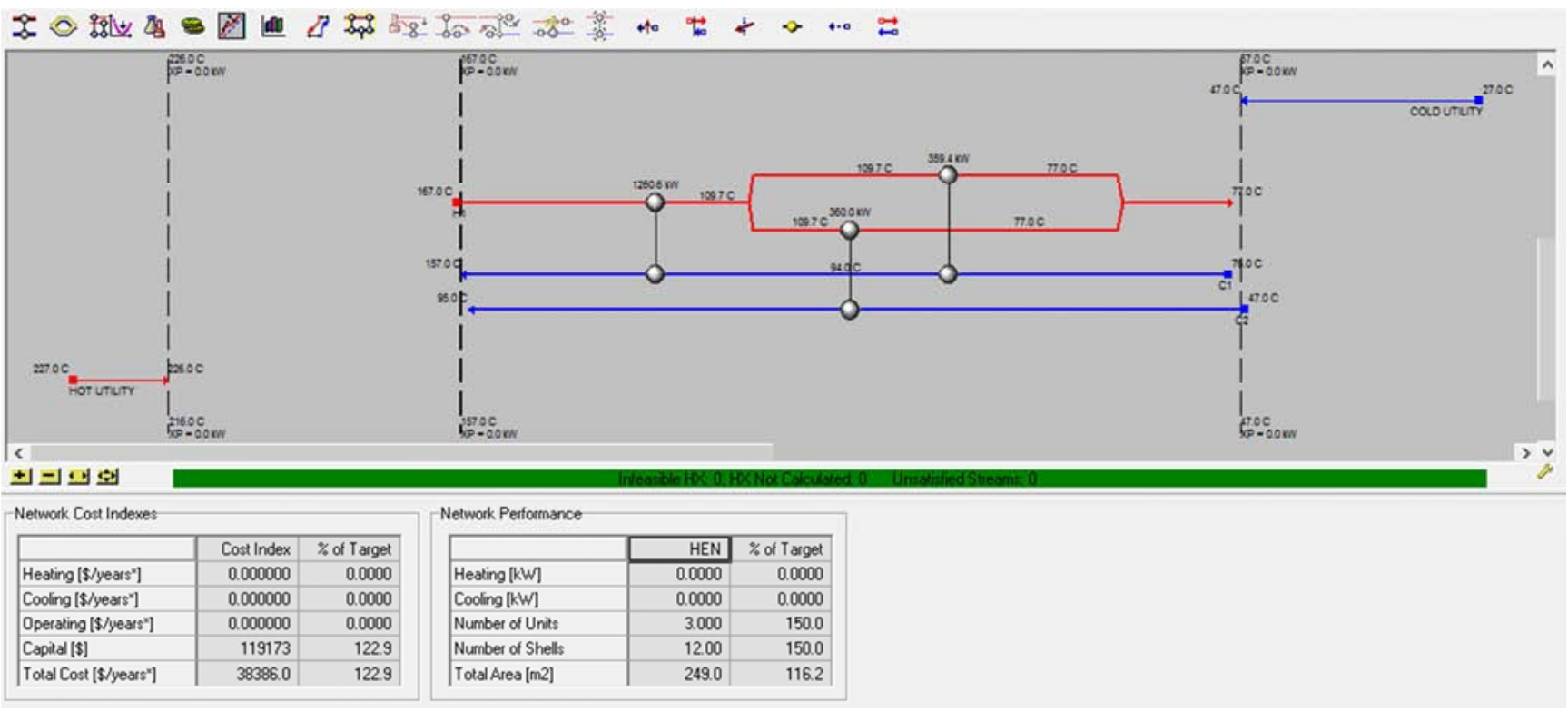

Figure 3. HEN design with isothermal stream mixing for case study 1. 


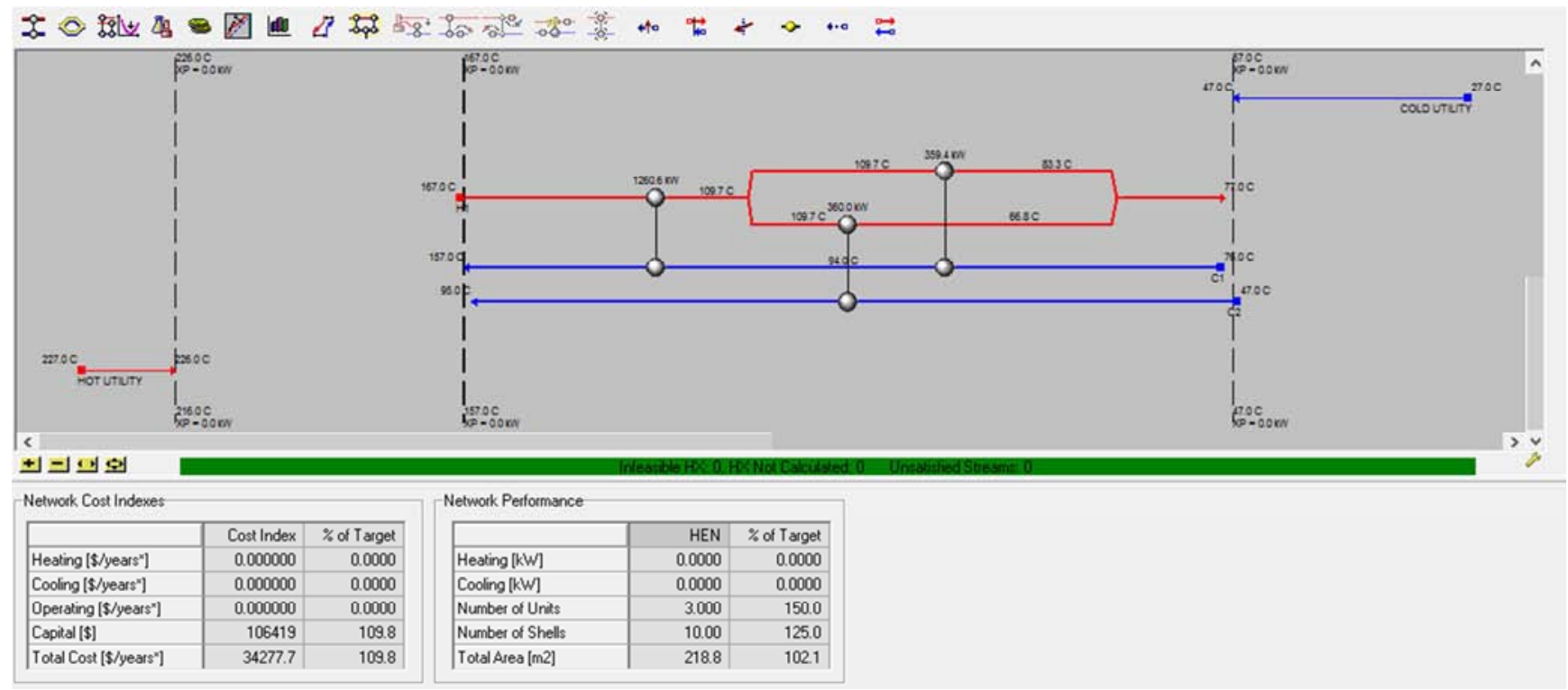

Figure 4. HEN design with non-isothermal stream mixing for case study 1.

Table 1. Stream and Cost data for Case Study 1

\begin{tabular}{|c|c|c|c|c|c|}
\hline Stream & $\mathbf{T}_{\text {in }}\left({ }^{\circ} \mathrm{C}\right)$ & $T_{\text {out }}\left({ }^{\circ} \mathrm{C}\right)$ & $h\left(k W C^{-1} m^{-2}\right)$ & FCp(Kw/K) & $\operatorname{Cost}\left(\$ \mathrm{kw}^{-1} \mathrm{yr}^{-1}\right)$ \\
\hline H1 & 167 & 77 & 2 & 22 & - \\
\hline $\mathrm{C} 1$ & 76 & 157 & 2 & 20 & - \\
\hline $\mathrm{C} 2$ & 47 & 95 & 0.67 & 7.5 & - \\
\hline $\mathrm{HU}$ & 227 & 227 & 1 & - & 120 \\
\hline $\mathrm{CU}$ & 27 & 47 & 1 & - & 20 \\
\hline
\end{tabular}

Heat Exchanger cost $=6600+670(\text { area })^{0.83}$

Table 2. Network Comparison for Case Study 1.

\begin{tabular}{llll}
\hline \multirow{2}{*}{ Method } & \multirow{2}{*}{$\boldsymbol{T}_{\boldsymbol{m i n}}\left({ }^{\circ} \mathrm{C}\right)$} & \multicolumn{2}{c}{ Total Annual Cost (TAC) \$/year } \\
\cline { 3 - 4 } & Isothermal Stream Mixing & Non-Isothermal Stream Mixing \\
\hline Global Optimization of Bjork and Westerlund, 2002 [4] & Not Stated & 76,350 & 76,330 \\
Modified Pinch Analysis (This work) & 10 & 35,848 & 35,051 \\
Modified Pinch Analysis & 20 & 58,700 & 57,923 \\
Modified Pinch Analysis & 30 & 83,866 & 83,514 \\
\hline
\end{tabular}

\subsection{Case Study 2}

This case study is based on a three stream problem with a hot utility and a cold utility from Bjork and Westerlund [4], its stream and cost data is given by Table 3. The dependence of the process HEN's total cost on $\Delta T_{\min }$ is shown by its supertargeting curve in Figure 5, from which the optimum value is obtained as $14 \mathrm{~K}$.

Table 3. Stream and Cost data for Case Study 2.

\begin{tabular}{llllll}
\hline Stream & $\mathbf{T}_{\text {in }}\left({ }^{\circ} \mathrm{C}\right)$ & $\mathbf{T}_{\text {out }}\left({ }^{\circ} \mathbf{C}\right)$ & $\mathbf{h}\left(\mathbf{k W ~ C}^{-1} \mathbf{m}^{-2}\right)$ & $\mathbf{F C p}(\mathbf{K w} / \mathbf{K})$ & $\mathbf{C o s t}^{\left(\mathbf{~} \mathbf{~ k w}^{-1} \mathbf{y r}^{-1}\right)}$ \\
\hline H1 & 150 & 45 & 2 & 20 & - \\
C1 & 60 & 120 & 2 & 11 & - \\
C2 & 20 & 120 & 2 & 12 & - \\
HU & 210 & 210 & 1 & - & 80 \\
CU & 5 & 15 & 1 & - & 20 \\
\hline
\end{tabular}

Heat Exchanger cost $(\$ /$ year $)=4000+700(\text { area })^{0.8}$

The network designed for this problem using modified pinch analysis in Aspen Energy Analyzer shown in Figure 6obtained a TAC of $\$ 23,891$ with an area of $120 \mathrm{~m}^{2}$. On optimization of this network using the Aspen Optimization tool with heat exchanger loads and split stream ratios as the optimization variables, the software obtained a non-isothermal mixing network (Figure 7) with TAC of \$23, 439 and area of $118 \mathrm{~m}^{2}$. These networks were compared with the TAC from other researcher's networks [4] for this problem in Table 4 to depict further the importance of the value of $\Delta T_{\min }$ in HENS. 


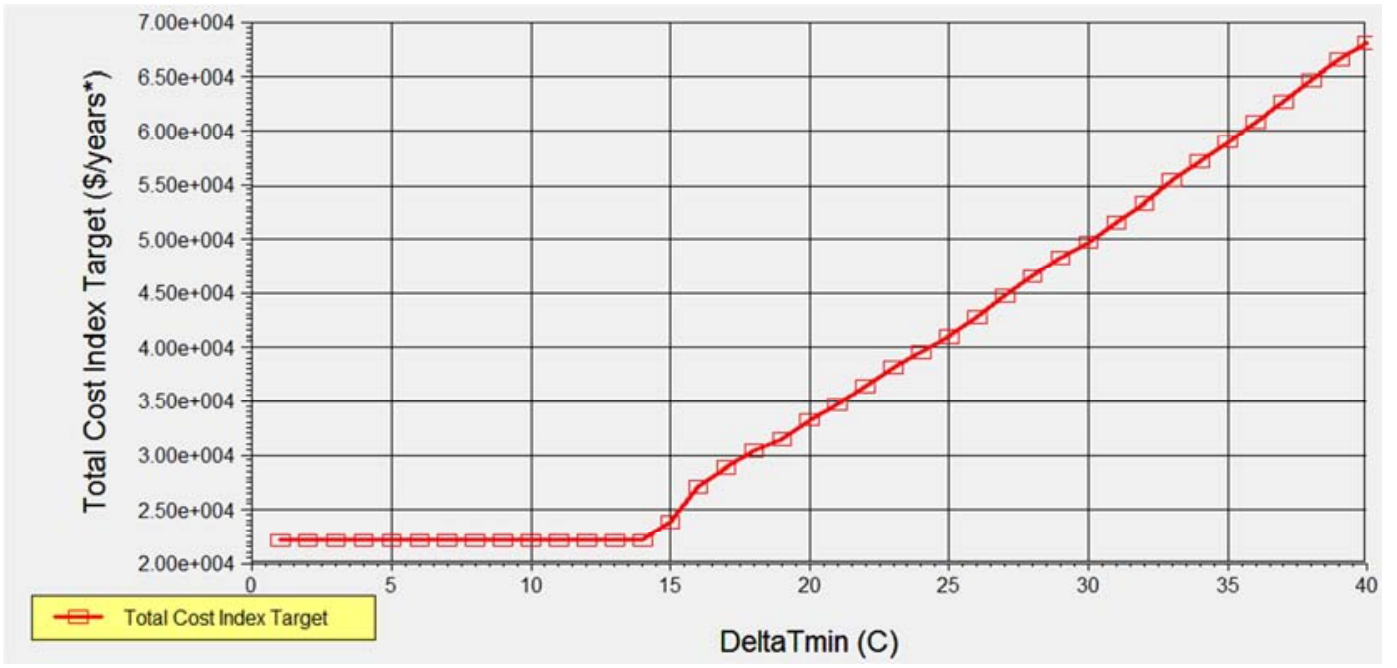

Figure 5. Supertargeting Curve for Case Study 2.

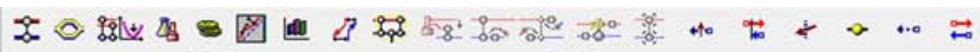

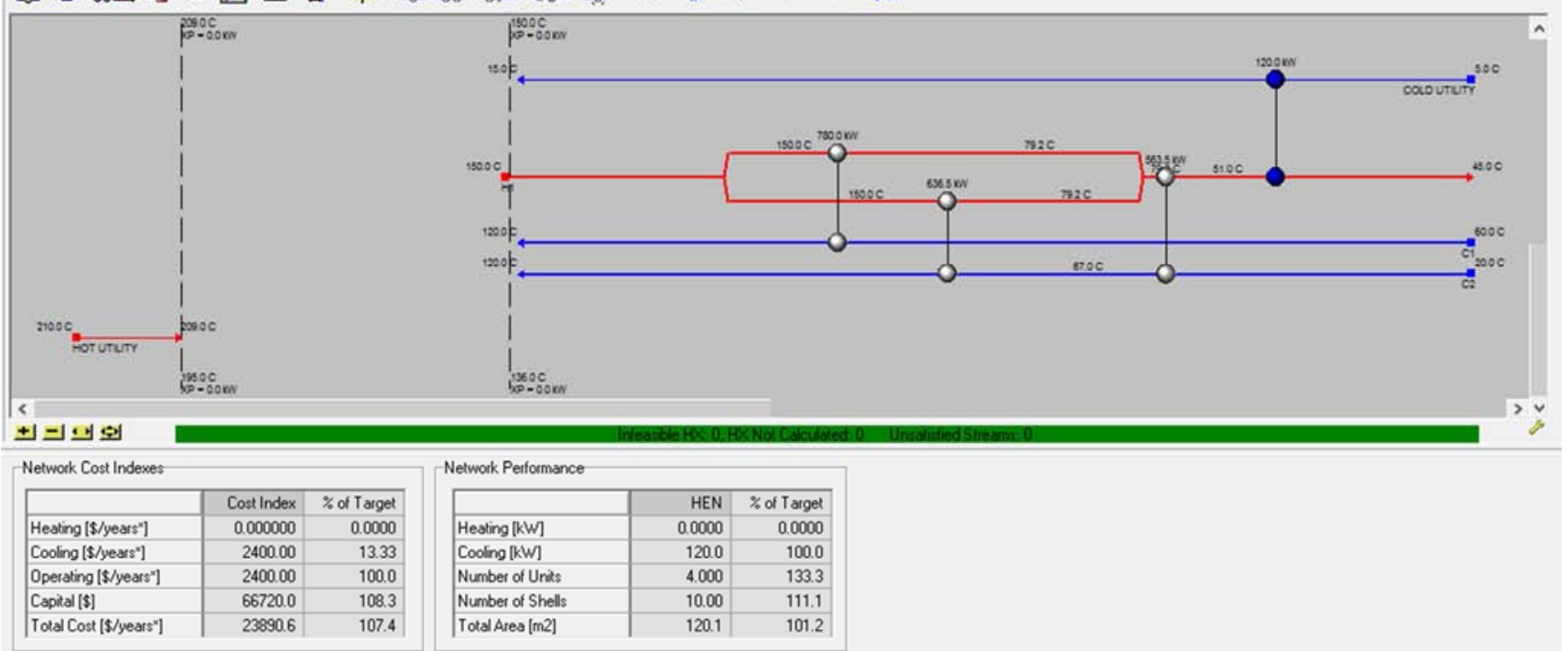

Figure 6. HEN design with isothermal stream mixing for case study 2.

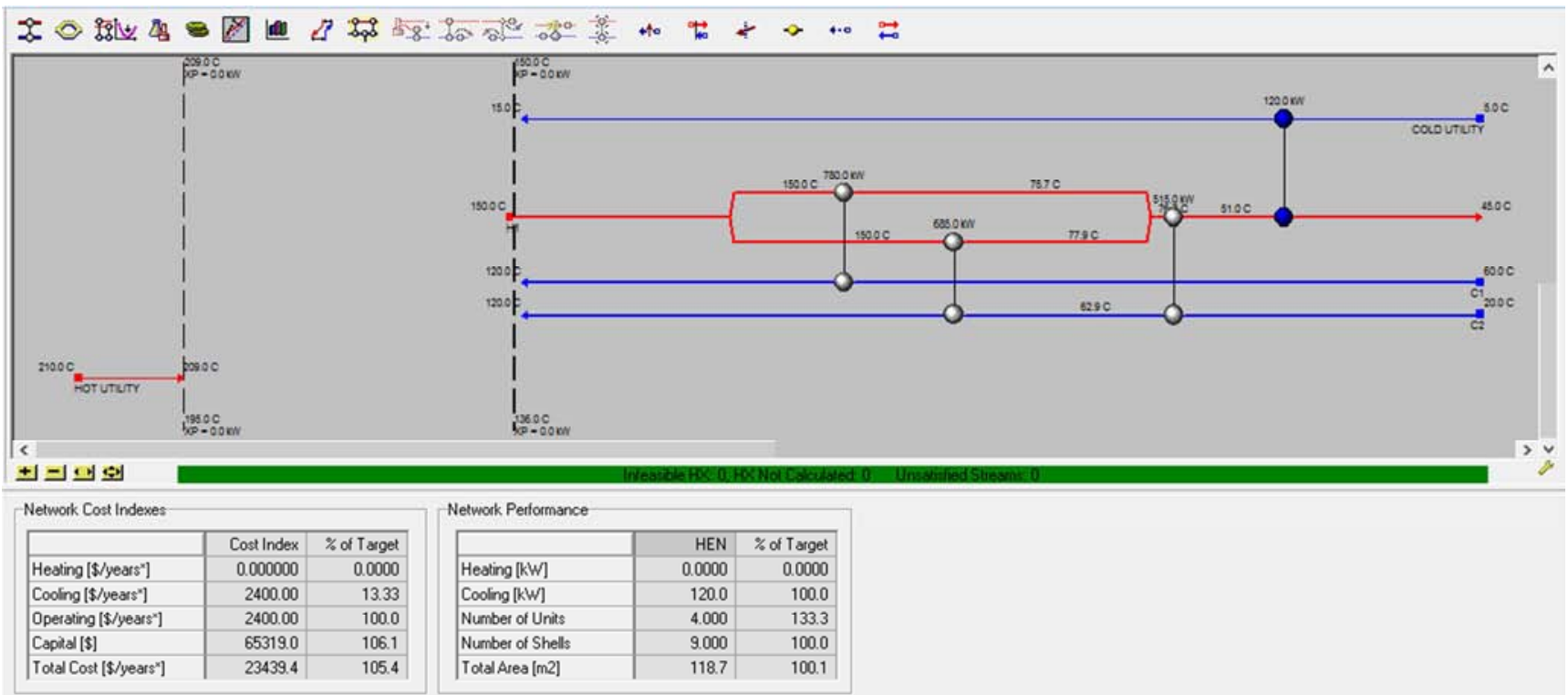

Figure 7. HEN design with non-isothermal stream mixing for case study 2. 
Table 4. Cost Comparison for Case Study 2.

\begin{tabular}{llll}
\hline \multirow{2}{*}{ Method } & \multirow{2}{*}{$\Delta \boldsymbol{T}_{\boldsymbol{m i n}}\left({ }^{\circ} \mathrm{C}\right)$} & \multicolumn{2}{c}{ Total Annual Cost (TAC) \$/year } \\
\cline { 3 - 4 } & \multirow{2}{*}{ Not Stated } & Isothermal Stream Mixing & Non-Isothermal Stream Mixing \\
\hline Global Optimization of Bjork and Westerlund, 2002 [4] & 14 & 23,491 & 48,625 \\
Modified Pinch Analysis (This work) & 25 & 41,733 & 23,439 \\
Modified Pinch Analysis & 35 & 61,385 & 41,212 \\
Modified Pinch Analysis & 60,865 \\
\hline
\end{tabular}

\subsection{Case Study 3}

Here a HEN was designed for a problem involving 2 hot streams and 2 cold streams using the Aspen Energy Analyzer software, the Stream and Cost data for this problem is displayed in Table 5. Supertargeting was carried out on the problem and a $\Delta T_{\min }$ value of $3^{\circ} \mathrm{C}$ as can be seen in the supertargeting curve on Figure 8, the network designed with the value and the isothermal stream mixing assumption (Figure 9) obtained TAC of $\$ 346,471$. The removal of the isothermal assumption through optimization of the designed network produced a non-isothermal network (Figure 10) with TAC of $\$ 325,328$. The networks designed in this work were compared with other works $[4,14]$ in Table 6 , Zamora and Grossmann [14] solved this same problem but without stream splits.

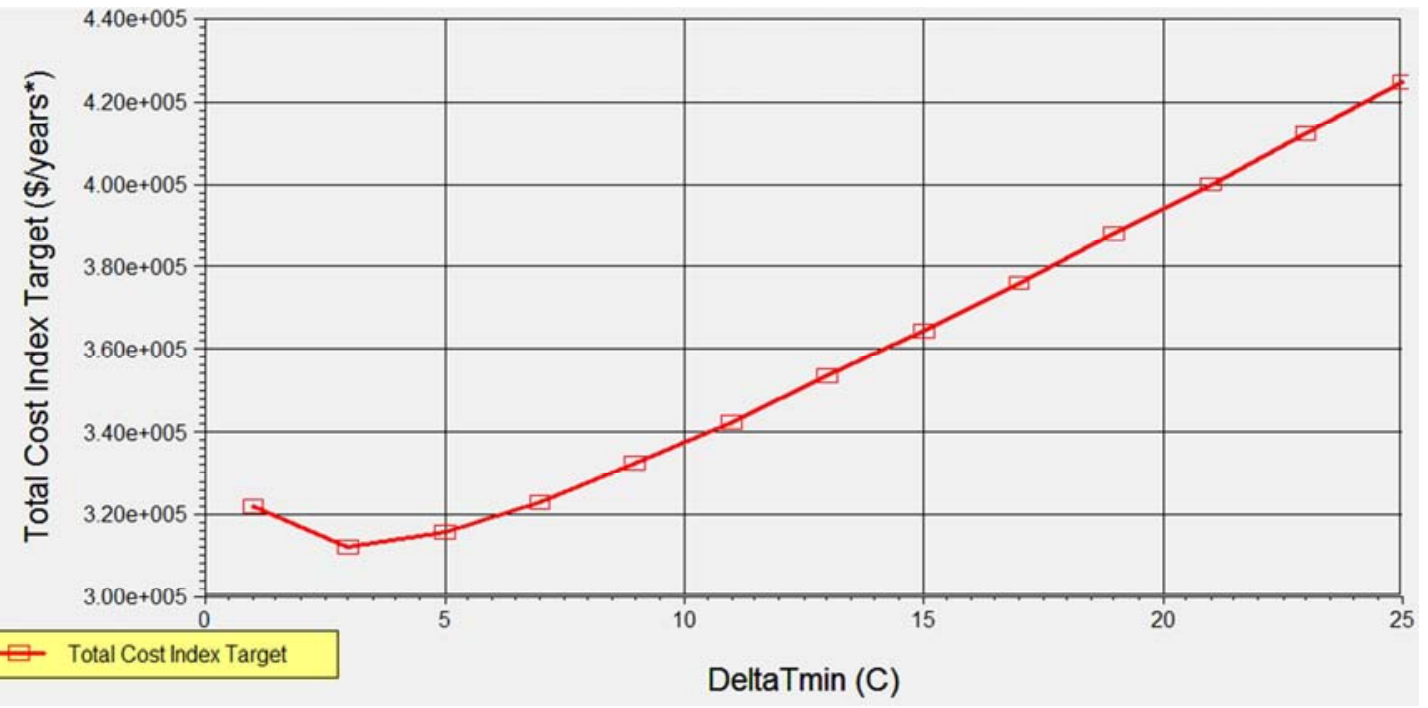

Figure 8. Supertargeting Curve for Case Study 3.

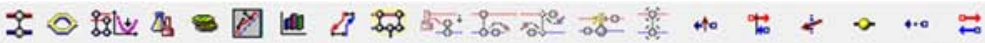

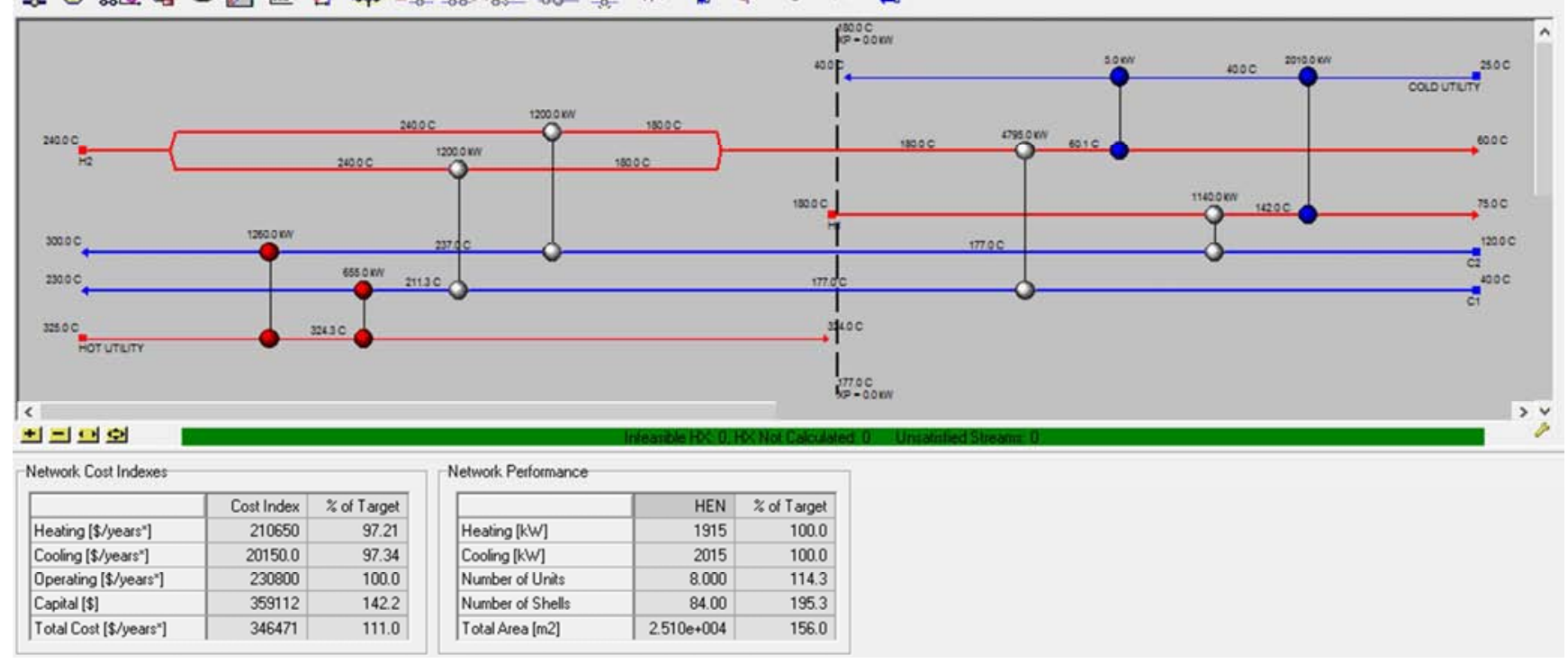

Figure 9. HEN design with isothermal stream mixing for case study 3 . 


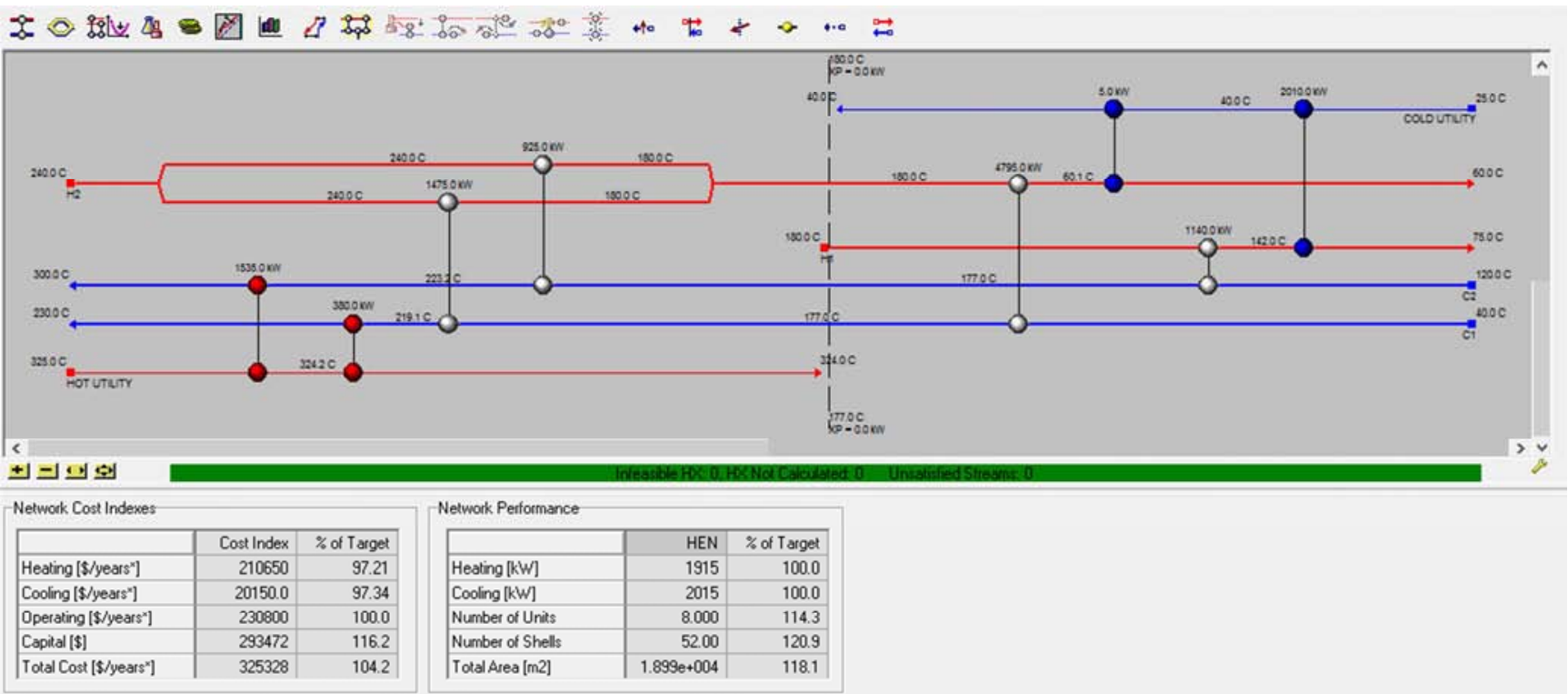

Figure 10. HEN design with non-isothermal stream mixing for case study 3.

Table 5. Stream and Cost data for Case Study 3.

\begin{tabular}{|c|c|c|c|c|c|}
\hline Stream & $\mathbf{T}_{\text {in }}\left({ }^{\circ} \mathrm{C}\right)$ & $\mathbf{T}_{\text {out }}\left({ }^{\circ} \mathrm{C}\right)$ & $\mathrm{h}\left(\mathrm{kW} \mathrm{C} \mathrm{C}^{-1} \mathrm{~m}^{-2}\right)$ & $\mathrm{FCp}(\mathrm{Kw} / \mathrm{K})$ & $\operatorname{Cost}\left(\$ \mathrm{kw}^{-1} \mathrm{yr}^{-1}\right)$ \\
\hline H1 & 180 & 75 & 0.15 & 30 & - \\
\hline $\mathrm{H} 2$ & 240 & 60 & 0.10 & 40 & - \\
\hline $\mathrm{C} 1$ & 40 & 230 & 0.20 & 35 & - \\
\hline C2 & 120 & 300 & 0.10 & 20 & - \\
\hline $\mathrm{HU}$ & 325 & 325 & 2 & - & 110 \\
\hline $\mathrm{CU}$ & 25 & 40 & 0.5 & - & 10 \\
\hline
\end{tabular}

Heat Exchanger cost $=15,000+30(\text { area })^{0.8}$

Table 6. Network Comparison for Case Study 3.

\begin{tabular}{llll}
\hline Method & $\Delta \boldsymbol{T}_{\boldsymbol{m i n}}\left({ }^{\circ} \mathrm{C}\right)$ & $\begin{array}{l}\text { Isothermal Network Cost } \\
\text { (\$/year) }\end{array}$ & $\begin{array}{l}\text { Non-Isothermal Network Cost } \\
\text { (\$/year) }\end{array}$ \\
\hline Bolio, 1994 [5] & Not Stated & 453,294 & - \\
Zamora and Grossmann, 1998[14] & Not Stated & 419,979 (no stream splits) & - \\
Bjork and Westerlund, 2002 [4] & Not Stated & 415,189 & 411,746 \\
This work & 3 & 346,471 & 325,328 \\
Modified Pinch Analysis & 15 & 374,205 & 371,720 \\
Modified Pinch Analysis & 25 & 431,806 & 430,911 \\
\hline
\end{tabular}

\subsection{Case Study 4}

Here, a 4 stream problem was solved to show the effect of $\Delta T_{\min }$ and non-isothermal stream mixing, the stream and cost data for this case study are shown in Table 7 . The process $\Delta T_{\text {min }}$ was determined using supertargeting as $5^{\circ} \mathrm{C}$ (Figure 11). The HEN designed for this problem (Figure 12) obtained a total annual cost of $\$ 49,774$, this network displayed in, on removal of the isothermal mixing assumption using optimization the total cost was reduced to $\$ 49,424$ as in the optimized network (Figure 13). These networks were compared to isothermal and non-isothermal solutions without the consideration of $\Delta T_{\min }$ [4] in Table 8.

Table 7. Stream and Cost data for Case Study 4.

\begin{tabular}{|c|c|c|c|c|c|}
\hline Stream & $\mathrm{T}_{\text {in }}\left({ }^{\circ} \mathrm{C}\right)$ & $\mathbf{T}_{\text {out }}\left({ }^{\circ} \mathrm{C}\right)$ & $h\left(k W C^{-1} m^{-2}\right)$ & FCp $(\mathrm{Kw} / \mathrm{K})$ & $\operatorname{Cost}\left(\$ \mathrm{kw}^{-1} \mathrm{yr}^{-1}\right)$ \\
\hline H1 & 227 & 147 & 1.60 & 6 & - \\
\hline $\mathrm{H} 2$ & 157 & 57 & 1.60 & 6 & - \\
\hline $\mathrm{H} 3$ & 147 & 67 & 1.60 & 7 & - \\
\hline $\mathrm{C} 1$ & 67 & 227 & 1.60 & 10 & - \\
\hline $\mathrm{HU}$ & 325 & 325 & 1.60 & - & 80 \\
\hline $\mathrm{CU}$ & 25 & 40 & 1.60 & - & 20 \\
\hline
\end{tabular}

Heat Exchanger cost $=1,000+560(\text { area })^{0.6}$ 


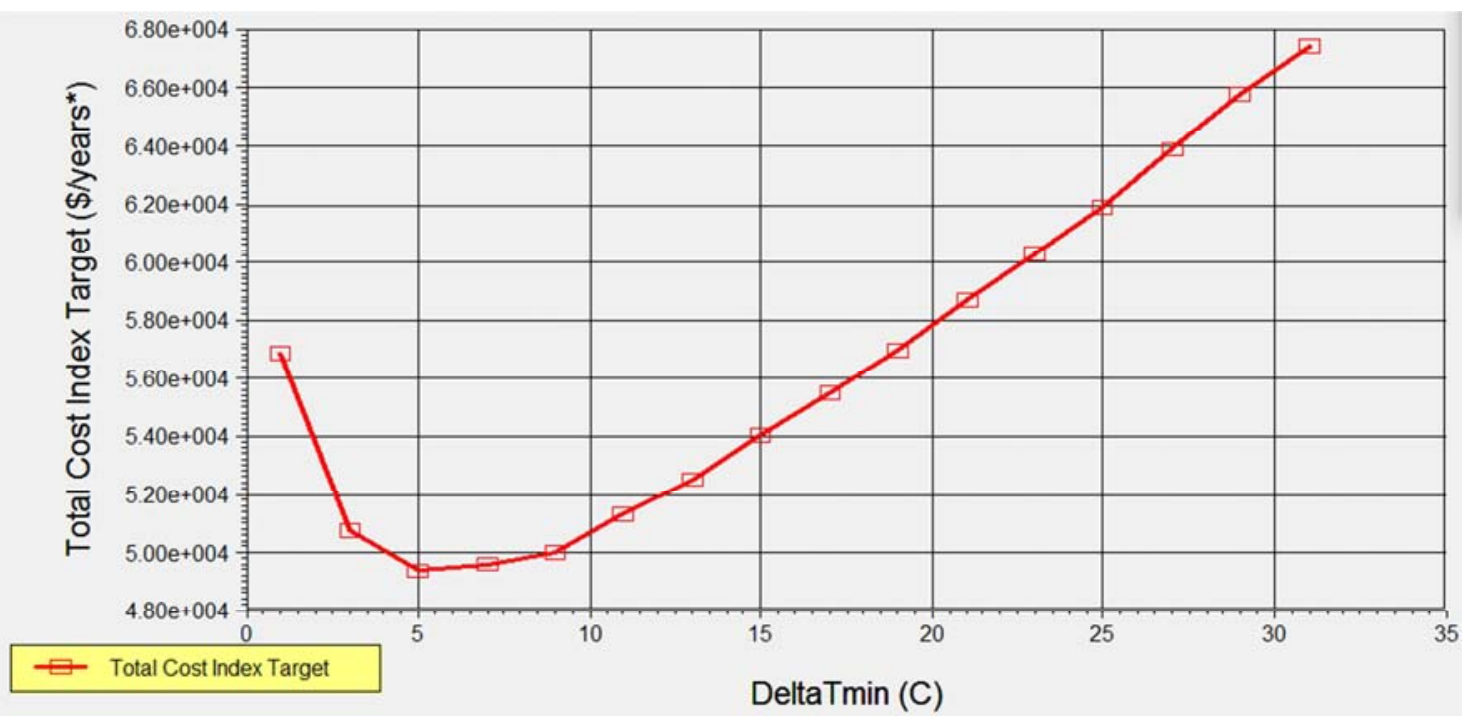

Figure 11. Supertargeting Curve for Case Study 4.

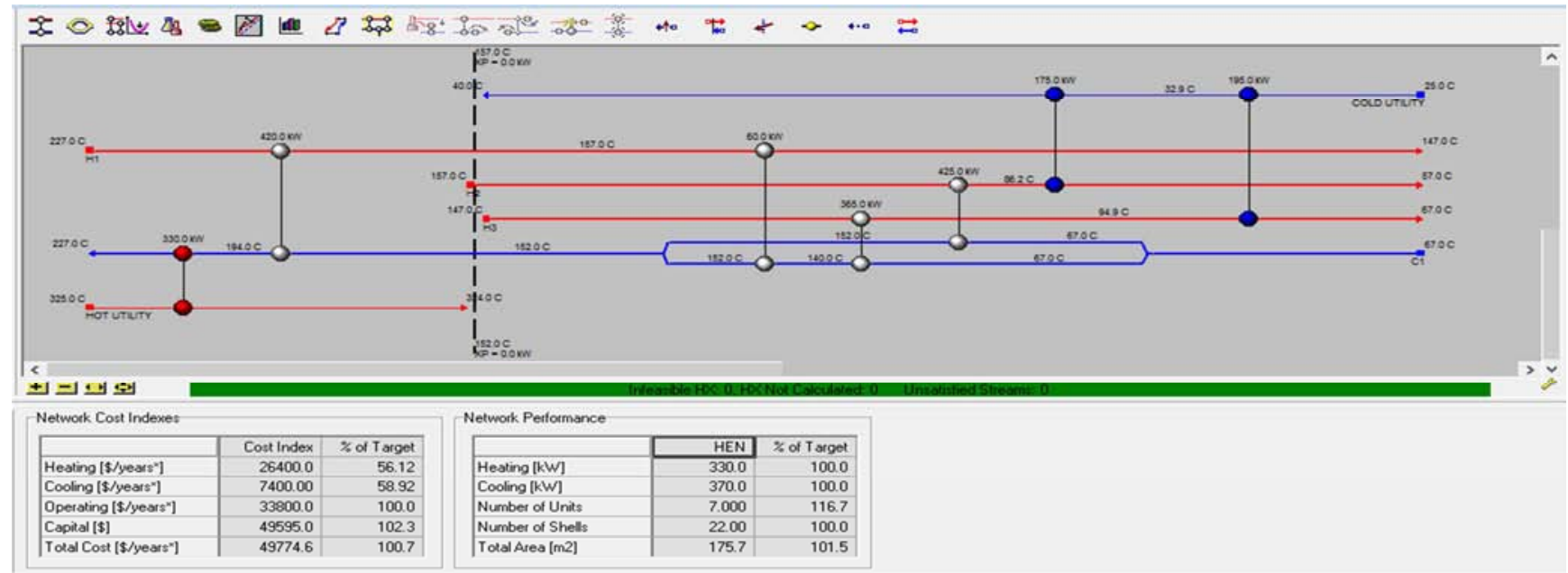

Figure 12. HEN design with isothermal stream mixing for case study 4.

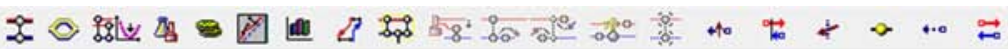

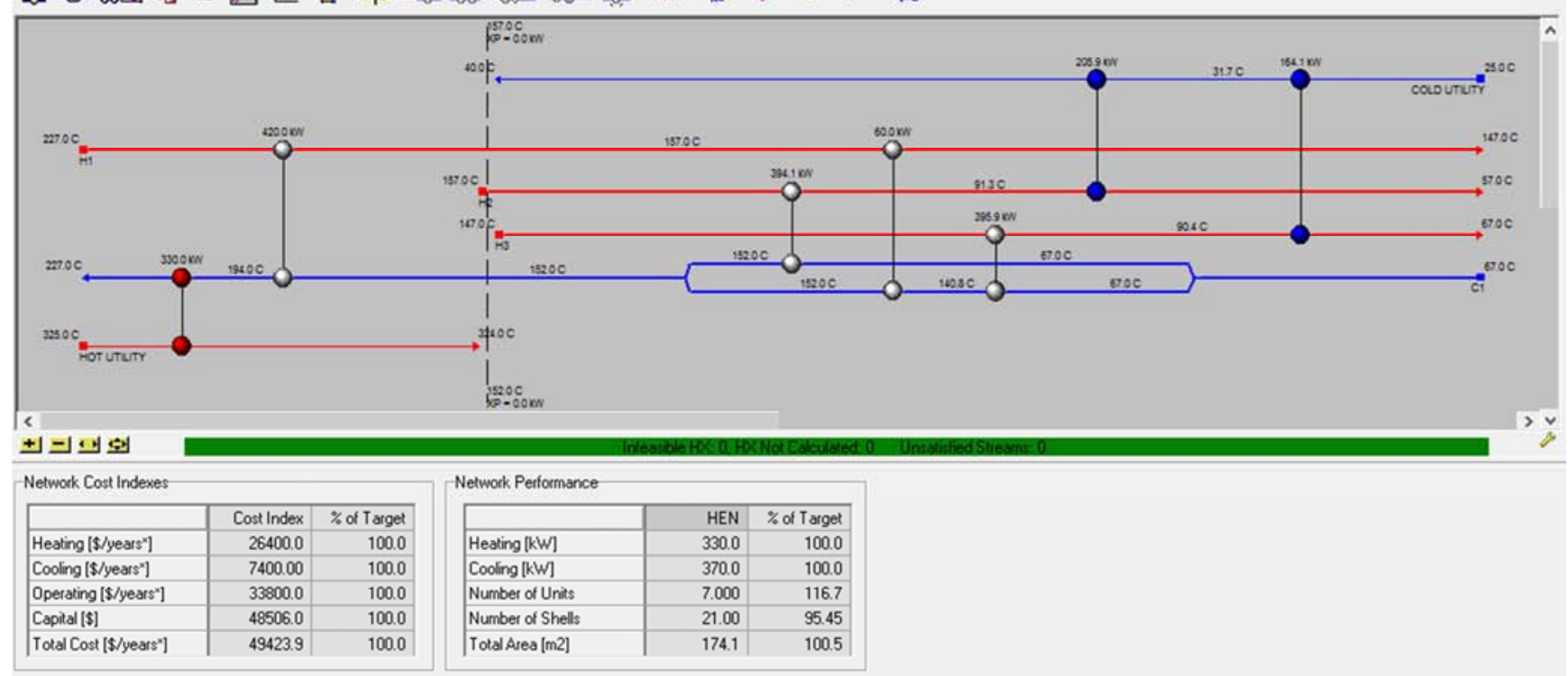

Figure 13. HEN design with non-isothermal stream mixing for case study 4. 
Table 8. Network Comparison for Case Study 4.

\begin{tabular}{llll}
\hline Method & \multicolumn{1}{c}{$\Delta \boldsymbol{T}_{\boldsymbol{m i n}}\left({ }^{\circ} \mathrm{C}\right)$} & Isothermal Network Cost (\$/year) & Non-Isothermal Network Cost (\$/year) \\
\hline Bjork and Westerlund (2002) [4] & Not Stated & 61,295 & 60,842 \\
Modified Pinch Analysis (This Work) & 5 & 49,774 & 49,424 \\
Modified Pinch Analysis & 15 & 54,041 & 53,774 \\
Modified Pinch Analysis & 25 & 61,809 & 61,805 \\
\hline
\end{tabular}

\section{Conclusion}

In the four case studies considered in this work, the effect of a minimum temperature difference $\Delta T_{\text {min }}$ can be clearly seen through the network comparison tables. The networks designed using the optimum $\Delta T_{\min }$ value from supertargeting obtained a lower TAC than those that were designed without considering this, the supertargeting curves for each case study show the range of costs associated with different values of $\Delta T_{\text {min }}$. Hence it is necessary to carry out supertargeting to determine $\Delta T_{\min }$ before HENS for optimum solution. The claim of global optimization will only be valid, if the $\Delta T_{\min }$ at which the optimization is carried is stated. The trend was confirmed in Network comparison tables of Case Studies 1-4 where TAC varied with $\Delta T_{\min }$ values.

For all the problems investigated, the TACs for nonisothermal mixing networks were considerably lower than those under the isothermal mixing assumption. This clearly shows that although the isothermal stream mixing assumption makes the HENS problem easier to solve, it does not lead to globally optimal networks and therefore optimization of the designed networks is necessary to remove this assumption and improve the network.

\section{References}

[1] Aspen Energy Analyzer Version 8.8, 2018.

[2] AspenTech (2018). Aspen Energy Analyzer; Reference Guide, Aspen Technology Inc, Burlington, USA.

[3] Azeez O. S., Isafiade A. J., \& Fraser D. M. (2012), Supply and target based Superstructure synthesis of heat and mass exchanger networks, Chemical Engineering Research and Design 90, pg 266-287.

[4] Bjork K. M. \&Westerlund T. (2002). Global optimization of heat exchanger network synthesis problems with and without the isothermal mixing assumption. ComputChemEng, 26:1581 -1593 .
[5] Bolio, B. (1994). Guidelines for the Synheat Interface. Department of Chemical Engineering, Carnegie Mellon University.

[6] Huang K. F., Al-mutairi E. M. \&Karimi I. A. (2012). Heat exchanger network synthesis using a stage wise superstructure with non-isothermal mixing. Chemical Engineering Science, $73,30-43$.

[7] Krishna M. Y. \& Murty C. V. S. (2008), Synthesis of costoptimal heat exchanger networks using differential evolution, Computers and chemical engineering 32, pg 1861-1876.

[8] Liang Z., Hongchao Y. \&Huo Z. (2016). Simultaneous synthesis of heat exchanger network with the non-isothermal mixing. International Journal of Low-Carbon Technologies, $11,240-247$.

[9] Linnhoff B. (1993), Pinch Analysis; A state of the art overview, Chemical Engineering Research and Design 71, pg 503-522.

[10] Linnhoff, B. and Ahmad, S. (1989). "Supertargeting: Optimum Synthesis of Energy Management Systems". ASME J. Energy Resource Tech., 111(3): 121-130.

[11] Linnhoff, B and Tjoe, T. N. (1986). "Using Pinch Technology for Process Retrofit". ChemEng, 47-50.

[12] OnyemachiJ. O. and Azeez O. S. (2018), Area Targeting of Heat Exchanger Network (HEN) Using a Modified Pinch Technique IOP Conf. Ser.: Earth Environ. Sci. 173012003.

[13] Yee T. F. and Grossmann I. E. (1990), Simultaneous Optimization models for heat Integration II; Heat Exchanger Network Synthesis. Computers and chemical engineering, 14(10) pp 1165-1184.

[14] Zamora J. M., \& Grossmann, I. E. (1998). A global MINLP optimization for the synthesis of heat exchanger networks with no stream splits. Computers \& Chemical Engineering, 22(3), 367-384.

[15] Zhao D., Paiko I. I., Azeez O. S. and Makwashi N. (2017), Pinch Analysis in Optimising Energy Consumption on a Naphtha Hydrotreating Unit in a Refinery, Pet Petro ChemEng Journal, 1(5): 000126. 